\title{
Entrevista COM o Prof. ERIK JAYME
}

Entrevista exclusiva para a Revista Trimestral de Direito Civil - RTDC, dirigida pelo Prof. Dr. Gustavo Tepedino (UERJ), para a seção "Díalogo com a Doutrina", Ed. Padma, Rio de Janeiro, tradução de Claudia Lima Marques. Republicação autorizada.

Fonte: Revista Trimestral de Direito Civil, ano 1, vol. 3 jul./set. 2000, p. 289-293

Erik Jayme

Catedrático da Universidade de Heidelberg, Alemanha

Diretor do Instruto para Direito Estrangeiro, Direito Internacional Privado e Direito Econômico da Universidade de Heidelberg, Alemanha

RTDC1.Quais são as suas principais lembranças sobre os seus estudos universitários? Quem foram os mestres que mais o influenciaram, qual era o método didático utilizado e como se dava a relação entre professores e alunos? Que peso teve a sua formação universitária no desenvolvimento de sua vida profissional?

- Estudos universitátios: Eu estudei três semestre na Faculdade de Direito de Frankfurt, enrão 5 semesrres Direiro e História da Arte na Universidade de Munique. Depois do primeiro exame de Estado, estudei um ano na Universidade de Pavia (Itália), onde escrevi meu Doutorado. Depois do segundo Exame de Estado, estudei um ano na Universidade de Berkeley, California e recebi o título de Master of Law (LL.M.).

O mestre, que mais influenciou meu pesamento, foi Albert A. Ehrenzweig, que ensinava Direito Internacional Privado em Berkeley. Ele vinha da Áustria, possuia um forte influência filosófica e uma impressionante maneira de vincular os problemas jurídicos com perguntas e questionamentos vindos da Psicologia. Ele via o Direito como um todo, trabalhava interdisciplinarmente. Hoje eu visualizo o Direito através das tendências - pós-modernas- da Filosofia. Eu agradeço a Ehrenzweig a coragem, para isto fazer. Eu aprendi também como se escreve cientificamente em Direito. Juntos publicamos dois livros em inglês.

A técnica do Direito Internacional Ptivado agradeço à Murad Ferid (Munique), de quem fui mais tarde sucessor - è Rodolfo De Nova (Pávia). De Hans G. Fiscker (Mainz) aprendi a não excluir o Direito da Arte. 
Meus modelos encontrei no passado. Pasquale Stanislao Mancini (1817-1888), liberal, aberto para o mundo, professor, ministro da Justiça e Advogado, foi o grande ídolo de minha vida, mais tarde também, para o Direito Comparado, Emerico Amari (1810-1879). O ideal vínculo entre Arte e Direito está no grande pintor Antonio Canova (1757-1822).

RTDC 2. Como comparar a Universidade alemã de ontem com a de hoje? No decorrer de sua experiência didática foram perceptíveis os momentos de transição, as inflexões relevantes no currículo, as alterações importantes de rumo?

- Quando eu tive a oportunidade de estudar, alcançavam a universidade apenas $5 \%$ dos alunos de Ginásio. Os estudantes vinham das classes mais altas e cultas da Burgesia; eu tinha estudado em um Ginásio Humanístico e aprendido 5 línguas ( 9 anos de Latin, 7 anos de grego, 5 anos de inglês, 3 anos de françes e 2 anos de Ialiano). Hoje os estudantes (aproximandamente $50 \%$ de todos os alunos de ginásio, na Alemanha, chegam na Universidade) trazem uma formação rotalmente diferente. Meu estilo de ensinat foi extremamente influenciado por minha passagem nos Estados Unidos. Incentivar e conduzir as aulas com perguntas. Eu prefiro a Aula através do Diálogo. Na minha época de estudante, falávamos apenas nos seminários, nunca nas aulas magistrais dos professores.

RTDC 3. Ao longo de sua experiência científica, como doutrinador, manteve-se fiel ao método apreendido durante sua formação acadêmica ou decidiu adotar outros critérios e perspectivas de investigação? A eventual mudança deveu-se a algum acontecimento particular, político ou pessoal?

- Até 1980 eu utilizava os métodos tradicionais da Dogmática civilística e os métodos de pensamento conflituais do Direito Internacional Privado. Então volteime, por algum tempo, totalmente para a evolução das Idéias Jurídicas, pois as idéias mudam a realidade. Minha simpatia voltou-se para os questionamentos, que também movimentavam minha pessoa e meu tempo, sobretudo a identidade cultural do indivíduo.

RTDC 4. A literatura, a poesia, as artes em geral contribuíram para a sua formação de jurista? Quem são os seus autores preferidos? Que leituras recomendaria às novas gerações? Que autores clássicos não devem deixar de ser conhecidos?

- Escritos jurídicos, que influenciaram minha vida, foram, por exemplo, Mancini, Il principio di nazionalità come fondamento del diritto delle genti (1851) ou Ehrenzweig, Psychoanalytic Jurisprudence (1971). Somente com mais idade consegui unir minhas duas áreas de interesse arravés do "Direito da Arre" (Kunstrecht). Eu amo ópera (Vincenzo Bellini, Richard Strauss), leio com prazer a lireratura austríaca (Hugo von Hofmannstahl, Robert Musil). Meu interesse principal é a pinruta, da Renascença (Giorgione) aré à pós-modernidade (Rainer F’etting). Às 
jovens gerações recomendaria eu, a leitura "Bildungsromane" (leitura sobre a formação do próprio indivíduo, do ser), recomendaria a leitura, por exemplo, de a Montanha Mágica de Thomas Mann.

RTDC 5. O que despertou seu interesse para o Direito Civil e o Direito Internacional Privado?

- Inicialmente me fascinou o Direito Internacional Público. Foi Ferid Murad que despertou meu interesse pelo Direito Civil Comparado e o Direito Internacional Privado. $O$ que me prende é a realidade, o destino humano (Schicksale), os caminhos e problemas dos indivíduos. Dai ter eu iniciado com o Direito de Família.

RTDC 6. Quais as sua impressões sobre os novos "movimentos" da civilística atual, em particular, a descodificação, os microssistemas, a constitucionalização do direito civil?

- Na Alemanha estamos agora recentemente incluindo as leis esparsas de proteção dos consumidores no Código Civil Alemão (BGB), especialmente na Parte Geral (\$ 13 Definição de Consumidor). ${ }^{1}$ Codificações claras facilitam, em minha opinião, a aplicação e interpretação do Direito (die Rechtsfindung). No mais, defendo o "Diálogo das Fontes".

RTDC 7. São conhecidos seus estudos acerca da codificação, e, de outro lado sobre a influência da cultura pós-moderna no direito. Neste sentido, entende ser oportuno e/ou necessário promulgar novos Códigos gerais?

- A existência de codificações diminui as antinomias e as contradições na ordem jurídica (die Widerspruchfreibeit der Rechtsordnung). No atual Código Civil Brasileiro, eu admiro a Parte Geral, que inclui também os atos ilícitos.

RTDC 8. Em tempos pós-moderno, de pluralismo de fontes nacionais e internacionais, normas cogentes e normas de inspiração, duas idéias suas têm chamado a atenção dos brasileiros, o que denominou "normas narrativas" e a necessidade de "diálogo das fontes". O senhor poderia esclarecer melhor estas suas expressões e teorias?

- Com a idéia de "normas narrativas" tento eu descrever alguns fenômenos. No Direito Internacional Privado alemão houve uma reforma em 1986 que duplicou os textos, Tratados Internacionais e uma codificação. Normas narrativas têm o sentido de indiçar ourros textos para aplicar. Então descobri normas que nenhum outro fim têm, senão descrever valores (por ex. Art.3,2 Convenção de Bruxelas de 1968). Normas narrativas nesre sentido

1 No original: "BGB- $\$ 13$ Verbraucher. Verbraucher ist jeder natürliche Person, die ein Rechtsgeschät zu einem $Z$ weck abschliesst, der weder ibrer gewerblichen noch ibrer sebständigen beruflichen Tätigkeit zugerechnet werden kann." (BGB. $\$ 13$ - Consumidor - Consumidor é qualquer pessoa física, que conclui um negócio jurídico, cuja frnalidade não tem ligação comercial ou com sua atividade profissional). 
são normas que trazem valores (Wertträgernormen), as quais ajudam no desenvolvimento do Direito (Fortentwicklung des Rechts) com orientações e ajudas. Dai retirei o vínculo com a "soft law", os códigos de conduta, deontológicos, ou as normas criadas por cientistas, como as normas de "crétion savante" (UNIDROIT), que não obrigam, apenas "iluminam". Finalmente conclui a ponte entre a Narração e o pós-moderno. Isto tem dois significados. Narração significa, em primeiro lugar, na arte, que o objeto de arte, também as edificações, irá descrever seu sentido, sua função. De outro, narração significa também legitimação. Valores só serão usados, quando são descritos e narrados. Por isto podemos entender o grande significado das Diretivas Européias. Elas contém inicialmente um descrição de sua finalidade e são elas mesmos um modelos de tegra para as legislações nacionais. $O$ "diálogo das fontes" significa, que decisões de casos da vida complexos são hoje o somat, o aplicar conjuntamente, de várias fontes (Constituição, Direitos Humanos, direito suptanacional e direito nacional). Hoje não mais existe uma fixa determinação de ordem entre as fontes, mas uma cumulação destas, um aplicar lado a lado. Os direitos humanos são direitos fundamentais, mas somente as vezes é possível deles retirar efeitos jurídicos precisos.

O Direito Civil hoje é determinado por cláusulas gerais, como Boa-fé, Equuidade, Bons Costumes, Ordem pública. Minhas reflexões partem da pergunta, como são estas cláusulas gerais concretizadas, com por exemplo standards vindos do Direito Comparado (Veja meu trabalho Métodos de Concretização da ordem pública de 1989) ou arravés dos Direitos Humanos (Veja meu trabalho, A Ordem pública nacional e a Integração européia, Viena 2000).

RTDC9. Outro tema recorrente em sua obra é o revival dos direitos humanos como Leitmotiv do direito da pós-modernidade. No cenário atual, como poderíamos buscar um maior equilíbrio entre as liberdades fundamentais e a implementação dos direitos sociais, especialmente nos países tidos como periféricos? Como harmonizar, tanto no plano interno como internacional, os princípios consagrados nas constituições nacionais com as diretrizes comunitárias?

- Meus escritos mais recentes contém uma crítica à livre circulação na Europa como valor máximo do Direito de Família europeu. Direitos das pessoas, em minha opinião, não podem ser tratados como mercadorias... Hoje direitos humanos estão íncluídos no Art. 6, 2 do Tratado da União Européia como princípios gerais do Direito Comunitário Europeu.

Em minha aula na academia de Direito Internacional de Haia em 2000, "A proteção da pessoa humana face à globalisação e o direito internacional privado", renrei alcançar a proteção do indivíduo através de um reforço na autonomia deste, ao mesmo tempo, que se crie e se assegure direitos de informação. 
RTDC 10. Qual é a herança mais preciosa que os estudos do Direito Civil oferecem ao séc. XXI?

- Para o novo século recomendatia eu dois valores: Autonomia e Transparência.

\section{NOVAS PUBLICAÇÕES DO PROF. ERIK JAYME}

Langue et Droit (Bruxelas, Ed. Bruylant 2000)

Rechtsvergleichung - Ideemgeschichte von Emerico Amari zur Postmoderne (Heidelberg 2000) (Direito Comparado e história das Idéias de Emerico Amari até a Pós-modernidade)

Nationaler order public und europäische Integration (Viena 2000) (Ordem pública nacional e Integraçõa européia)

Rechtsschutz für ikonographische Programme historischer Gärten (Conferência Viena 2000)

(Proteção jurídica de programas iconográficos)

Zum Jahtrausendwechsel: Das Internationale Privatrecht zwischen Postmoderne und Futurismus, IPRAX 3/2000, p. 165 e seg. (Mudança do século: $O$ Direito Internacional Privado entre Pósmodernidade e Futurismo)

Antonio Canova: die politische Dimension der Kunst (Frankfurt7Main 2000) (Antonio Canova: A Dimensão Política da Arte) 